\title{
Enduring Ties to Community and Nature: Charting an Alternative Future for Southeast Alaska
}

\author{
JESSICA D. ULRICH AND THOMAS G. SAFFORD
}

\section{The Changing Face of Rural Alaska}

ก The precipitous decline of resource-extractive industries and increasing out-migration has raised questions about the social and economic future of some places in rural America. Nowhere are these uncertainties more evident than in Southeast Alaska. International competition, changing regulations, and shifting consumer preferences have hit commercial forestry and fishing operators hard, increasing unemployment and creating difficult economic conditions. Like residents of other transitioning rural communities across the United States, Southeast Alaskans confront difficult questions about possible paths forward. Should they abandon resource extraction and incentivize new industries to create jobs? Is sacrificing the traditional character of their community necessary to ensure economic survival? Does the grim future outlook mean leaving rural Alaska is the only viable option? Although economic disruptions in the region pose serious challenges, residents have strong social ties to their towns and villages as well as Alaska's unique natural amenities. These connections to people and place are important resources that may ultimately determine the resilience and survival of rural Alaskan communities.

In this brief we use survey data from the Carsey Institute's Community and the Environment in Rural America (CERA) project to analyze how residents of Ketchikan Gateway Borough and the Prince of Wales-Hyder Census Area in Southeast Alaska view the social challenges facing their communities as well as future prospects. Specifically, we investigate residents' connections to both community and the natural world, and how these ties shape their outlook about the region's future. This research provides important insights that can inform efforts by policy makers and civic organizations to support community development not only in Southeast Alaska, but across rural America.

\section{Key Findings}

- Over the past decade, the Ketchikan region of Southeast Alaska has lost 8.4 percent of its population. One out of every five survey respondents plans to leave the area within the next five years. Seventy-seven percent of respondents cited the lack of job opportunities as a problem in their community. ${ }^{1}$

- Environment-related reasons such as natural beauty of the area, and outdoor or other recreational opportunities, are the most important reasons to stay in the region. For Native Alaskans, ${ }^{2}$ cultural or religious roles in their community were also very important reasons to stay.

- Southeast Alaskans were divided about whether to maintain the character of their community or encourage new development, with 61 percent favoring economic development even if it changes the character of their communities.

- Using or conserving natural resources also split Southeast Alaskan communities. Forty-seven percent favored using resources to create jobs; 24 percent favored conserving them for future generations; while 29 percent viewed use and conservation as equally important.

- Most residents of Southeast Alaska see their community changing little in the next ten years. However, 39 percent of Alaskan Natives and 18 percent of non-Natives believe their community will be a better place to live in the future.

- Southeast Alaskans expressed high levels of civic culture, social capital, and community engagement. However, about half of the residents lack confidence in the local government to solve important problems. 


\section{CERA Southeast Alaska Survey}

Since 2007 the CERA project has surveyed almost 19,000 rural Americans from thirteen diverse locations across the United States with the goal of enhancing understanding about connections between changing social, economic, and environmental conditions. During the summer of 2010, 509 randomly selected residents of the Ketchikan Gateway Borough (KGB) and Prince of Wales-Hyder Census Area (PWH) in Southeast Alaska were surveyed. ${ }^{3}$ In each telephone survey respondents were asked approximately 100 questions about their backgrounds and opinions on a variety of socioeconomic and environmental issues. KGB and PWH were chosen because of their continued dependence on resource-extractive industries including commercial and guided sport fishing, mining, and timber harvesting and processing.

\section{Socioeconomic and Demographic Change in Southeast Alaska}

Part of the "Alaska Panhandle," KGB and PWH are the two southernmost Alaskan boroughs and census areas (see Figure 1). ${ }^{4}$ Rugged mountain ranges, forested islands, intercoastal waterways, and glaciers characterize the landscape. ${ }^{5}$ Most areas of Southeast Alaska can only be reached by plane or boat, thus, except for a handful of small communities, the region is sparsely populated (18,565 residents in both KGB and $\mathrm{PWH}^{6}$ ) and inhabitants are often geographically isolated from urban areas.
The majority of Southeast Alaskans are non-Hispanic white (65 percent) while Alaskan Natives are the predominant minority group. Natives constitute 15.7 percent of the population in KGB and 38.9 percent in $\mathrm{PWH}$, giving the combined area a Native population of 27.3 percent. Twentysix percent ${ }^{7}$ of survey respondents identified their race to be Native American/Alaska Native which well represents the actual percentage. These respondents most often identified with the Tlingit, Haida, and Tsimshian tribes which are the most populous in the region. ${ }^{8}$ With Natives such a key segment of the population, we found it important to distinguish between Native and non-Native views about community and environmental concerns in our analysis.

Both KGB and PWH had relatively stable populations throughout the 1960s followed by substantial growth from 1970 to 1990 (see Figure 2). ${ }^{9}$ This population growth was driven in a large part by the booming timber, fishing, and mining industries that promised new residents high-paying jobs. ${ }^{10}$ During the 1990s, KGB continued to increase slightly in population while $\mathrm{PWH}$ began to slightly decline. More recently (from 2000 to 2009) both areas have seen their populations decline (see Figures 1 and 2) with KGB losing 7.5 percent of its total population and PWH losing 9.2 percent. ${ }^{11}$ The Native population decreased 6.6 percent since 2000; however, this is lower than the non-Native loss of 8.4 percent. ${ }^{12}$ The precipitousness of this population decline leads one to ask why both the Native and non-Native populations in Southeast Alaska are losing population and how can we account for their differences and predict future trends?

\section{Figure 1. Average Annual Growth Rate in Alaska from 2000-2009 by Borough}

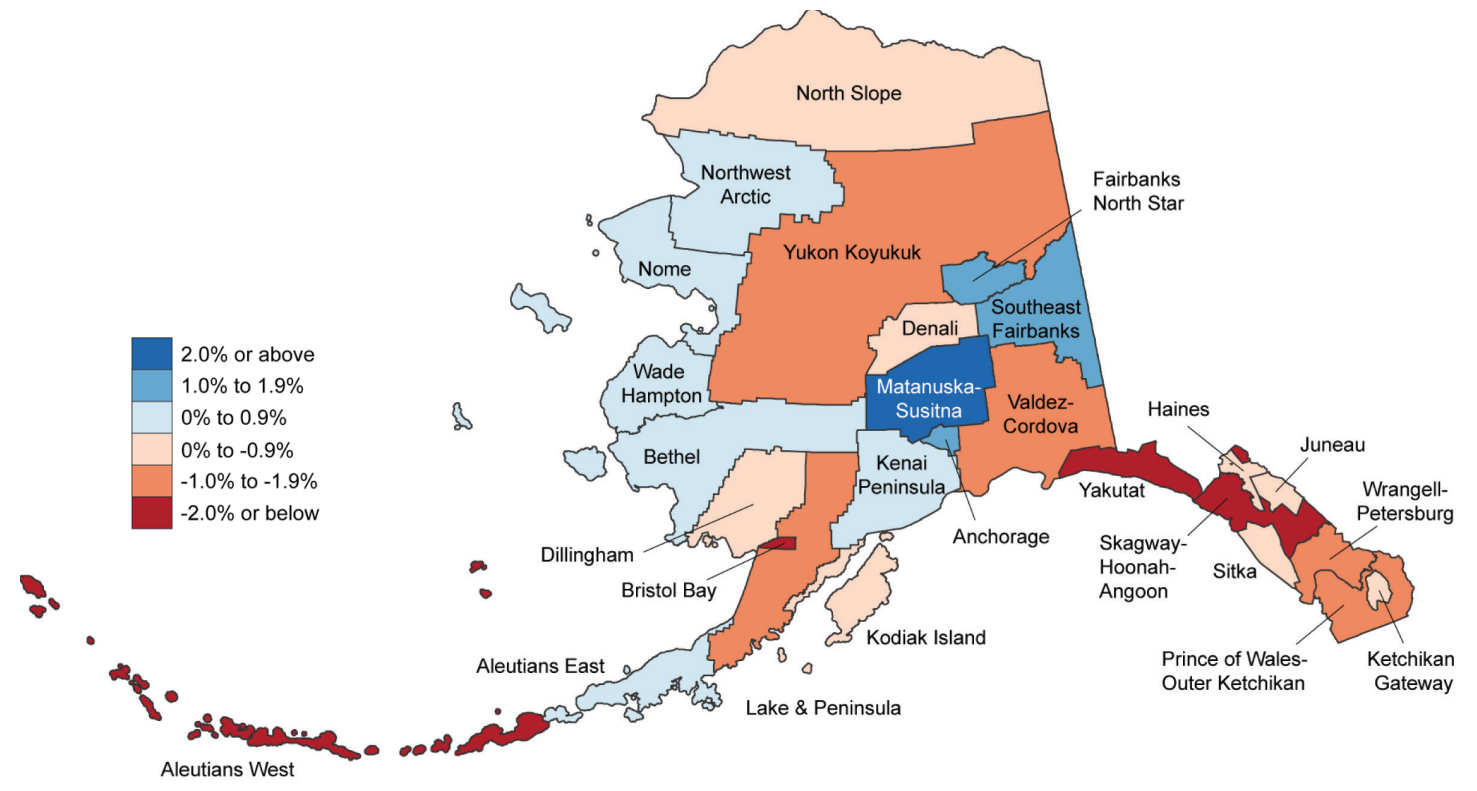


Figure 2. Demographic Change in Southeast Alaska over the Past 50 Years by Borough/Census Area

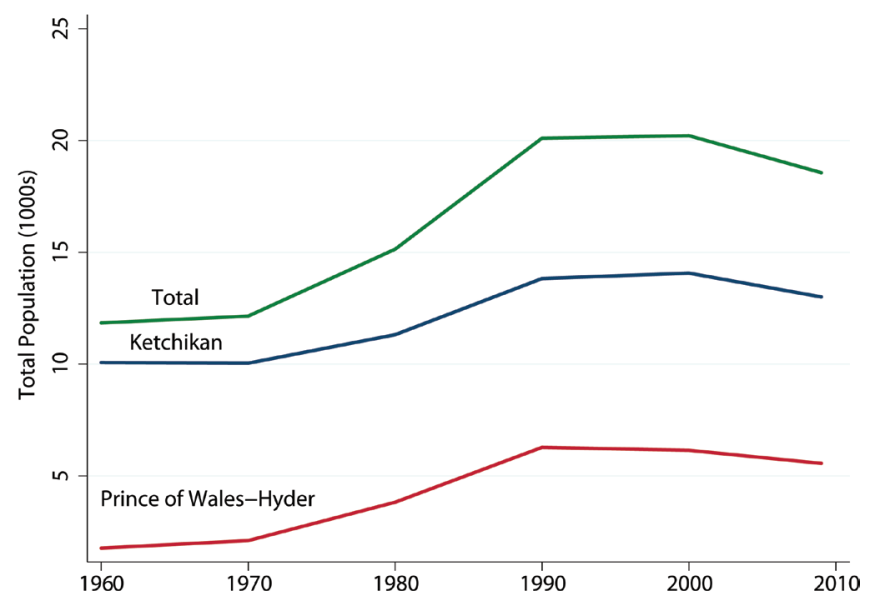

As in other parts of rural America, fluctuations in Southeast Alaska's population can be attributed to the booms and busts in its resource-dependent industries. Changes in resource regulations, depletion of natural resources, consumer demand, and global competition have all played roles in the ups and downs of the social and economic history of the region. Thus the drastic loss of jobs in these resource-dependent industries coupled with the difficulty of finding new jobs or even commuting to nearby towns has contributed to the out-migration of many Southeast Alaskans. These trends raise questions about the future of these communities. The CERA project sought to assess residents' views about both these trends and the future of Southeast Alaskan communities.

\section{Southeast Alaskans' Ties to Community and the Environment}

To assess Alaskans' connections to their communities, as well as understand possible future demographic trends, we first looked at residents' intentions to stay in the region. When asked about their plans to continue living in the area for the next five years, one out of five respondents said they intended to leave. Although this percentage is comparable to other regions surveyed by the CERA project, ${ }^{13}$ differences become more pronounced when race is taken into account.

Twenty-four percent of non-Natives said they planned to move away in the next five years, as compared to only 11 percent of Natives. Given the overall demographics of the region, this means that approximately nine out of every ten residents who plan to leave Southeast Alaska are non-Native. Why is it that more non-Natives plan to move away from their communities in the future? Do they have fewer ties to their communities or the area's natural amenities? In order to understand what ties residents to their communities or prompts them to leave, we asked respondents which factors they considered important when contemplating whether to stay or leave their community in the future.

\section{Roots in Family, Community, and a Rural Alaskan Lifestyle}

Results from the CERA survey illustrate that residents of KGB and PWH are strongly connected to both their communities and the region's natural amenities (see Figure 3). These ties to people and place likely influence both migration decisions as well as assessments of the future prospects for the region. Many of the valued attributes are shared by all Southeast Alaskans, but for a number of factors there are marked differences between Native and non-Native Alaskans.

General quality of life, natural beauty of the area, outdoor or other recreational opportunities, job or employment opportunities, and educational opportunities were of equal importance to Native and non-Native Alaskans. Both groups of respondents most frequently cited quality of life as a very important reason for staying. Approximately three out of every four respondents said that the general quality of life and natural beauty of Southeast Alaska are very important reasons for remaining in the area. Fifty-eight percent of both Natives and non-Natives cited outdoor and other recreational opportunities as very important. Job or employment opportunities were very important to 53 percent of non-Natives and 42 percent of Natives. Finally, educational opportunities were very important to less than 30 percent of respondents.

FIgURE 3. DO THE FOLLOWING THINGS SEEM NOT IMPORTANT, SOMEWHAT IMPORTANT, OR VERY IMPORTANT TO YOU WHEN YOU THINK ABOUT WHETHER YOU WILL STAY HERE OR MOVE AWAY IN THE FUTURE?

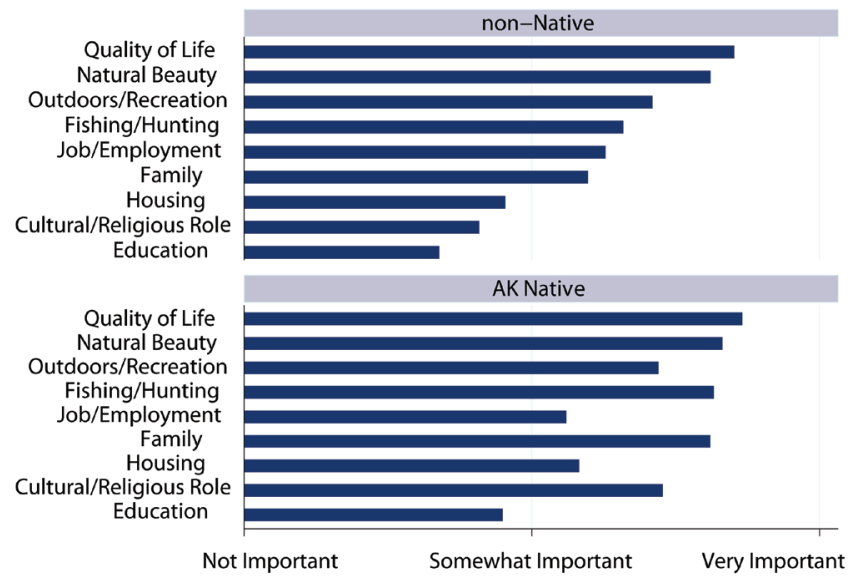


Nonetheless, there were marked differences in how Natives and non-Natives viewed the importance of the local environment and community characteristics. Three out of every four Native respondents said that the "ability to hunt, fish, harvest, or gather wild fish, game, or plants” was very important to them in comparison to little more than half of non-Natives. This suggests a greater reliance on the land and/or ocean as a source of food and/or income for Natives than for non-Natives. Living near family was also extremely important to Native Alaskans. Seventy-three percent of Natives cited living near family as very important while only 50 percent of non-Natives cited it as very important. ${ }^{14}$

The most striking difference was between how Native and non-Natives viewed the importance of their cultural or religious roles in their community. Sixty percent of Alaska Natives said that cultural or religious roles in their community were very important reasons to stay while only 25 percent of non-Natives did. Conversely, 44 percent of non-Natives said that cultural and religious roles were not important in comparison to only 15 percent of Alaska Natives.

That cultural and religious roles play such a large part in Alaska Natives' decisions to stay in their communities indicates how closely Native culture is tied to place and this may explain why they outmigrate at lower rates than non-Natives. The strength of Native Alaskans' cultural and religious ties might be an asset that these communities can use to both cope with difficult social or economic problems and create a more prosperous future that builds on familial and community bonds as well as the central importance of the environment to their individual and collective lives.

Rather than favoring practical reasons to stay in rural Alaska such as education, housing, or employment opportunities, residents of KGB and PWH see connections to family, community, and the region's natural amenities as more important. The beauty of the area, general quality of life, and outdoor or other recreational opportunities rank as highly important to most residents. For both non-Natives and $\mathrm{Na}$ tives, the four most frequently cited reasons for staying were all in some way related to the environment. The finding that environmental factors rank high for both groups indicates the importance of the natural characteristics of the region for all segments of the population. Understanding how this strong attachment to the natural world both facilitates and constrains these communities future prospects is thus a critical area for analysis.

\section{Jobs, Community, and the Environment: Confronting Development Tradeoffs}

The coastal forests and ocean environment are an integral part of the social and economic well-being of Southeast Alaska. Fishing and forestry remain the dominant industries in the region; however, they have steadily declined in recent years. These changes have implications not only for the health of the local economy, but also for the character of rural Alaskan towns and villages with their emblematic working waterfront and saw mills. To better understand these how social, economic, and environmental conditions are linked, CERA survey respondents were asked a series of questions about current economic conditions and the tradeoffs between different types of development.

More than three-quarters of respondents cited lack of job opportunities as an important problem facing their community, and these patterns were consistent across racial groups (see Figure 4). Given these difficulties with employment, we sought to assess how residents of KGB and PWH viewed the tradeoffs between conserving natural resources versus expanded resource extraction to create jobs. Our findings show that there is continued support for economic uses of forest and fishery resources. However, a significant portion of the population believes conserving natural resources for future generations is important as well (see Figure 5).

FIGURE 4. IS A LACK OF JOB OPPORTUNITIES AN IMPORTANT PROBLEM FACING YOUR COMMUNITY TODAY?

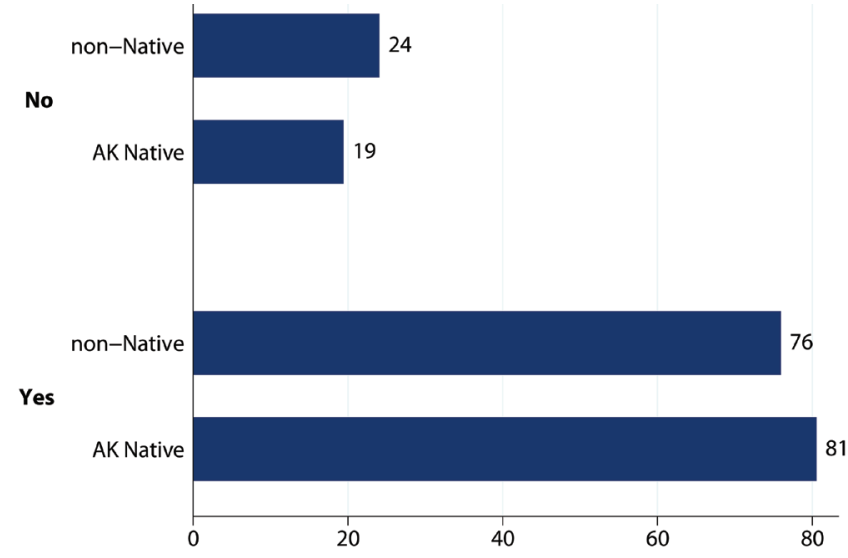


FIGURE 5. FOR THE FUTURE OF YOUR COMMUNITY, DO YOU THINK IT IS MORE IMPORTANT TO USE NATURAL RESOURCES TO CREATE JOBS, OR TO CONSERVE NATURAL RESOURCES FOR FUTURE GENERATIONS?

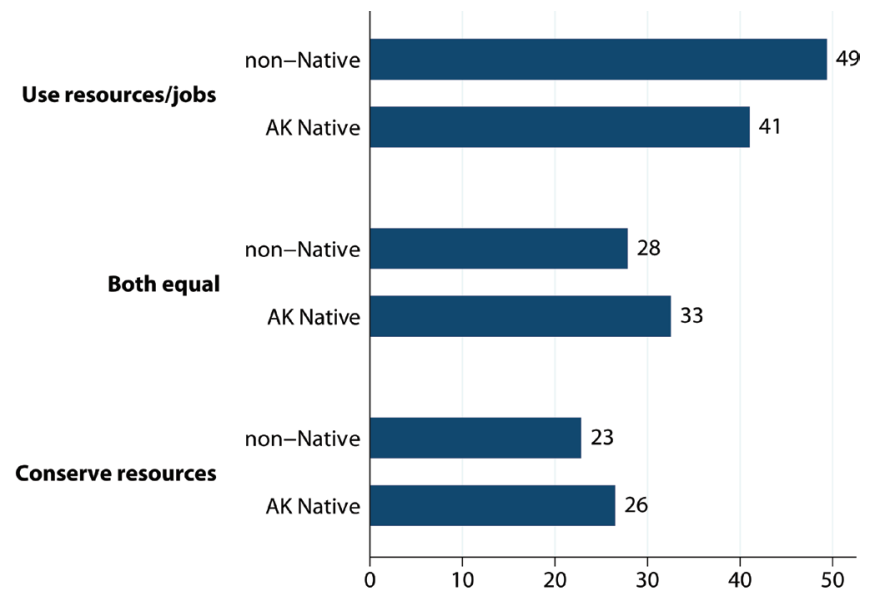

Forty-seven percent of respondents saw an immediate need to use natural resources to create jobs, but 53 percent indicated that either resources should be conserved for future generations or that use and conservation were equally important. Native Alaskans were slightly more inclined to focus on conservation for the future, but utilizing fishery and forest resources to create jobs was important to all segments of the population. The fact that a significant portion of Southeast Alaskans support conservation of natural resources, even when facing a severe lack of employment opportunities, suggests that residents see the environment as having more than an immediate extractive value. These findings are consistent with those in Figure 3, highlighting the social importance of natural amenities to Southeast Alaskans. Fishing and forestry activities are integral parts of rural Alaskan communities. Nonetheless, many residents recognize that economic uses must be balanced with conservation of these resources for future generations as well as other social uses.

Difficult tradeoffs between the use and conservation of natural resources is not the only issue Alaskan communities face when considering development alternatives. The character of towns and villages along the coast reflect the region's long-standing connections to the fishing and forestry industries. To gauge how important these community characteristics are to residents, CERA survey respondents were asked to assess the potential impact of new development on the character of their communities (see Figure 6).

Although a majority of respondents favored alternative types of development that increase employment, nearly 40 percent saw preserving the character of their community as more important than jobs. This support for preserving community character was strongest among Native Alaskans. Clearly, encouraging new development that increases employment is a priority for residents of KGB and PWH. Nonetheless, many Southeast Alaskans are unwilling to sacrifice the valued social and environmental characteristics of the region in order to create jobs.

FIGURE 6. WHEN YOUR LOCAL GOVERNMENT IS CONSIDERING FUTURE DEVELOPMENT IN YOUR TOWN, WHICH DO YOU THINK IS MORE IMPORTANT-“PRESERVING THE TRADITIONAL CHARACTER OF MY TOWN, SUCH AS PROTECTING HISTORIC BUILDINGS, FARMS, OR WORKING WATERFRONT, EVEN IF IT MEANS FEWER NEW JOBS" OR "ENCOURAGING ECONOMIC DEVELOPMENT THAT BRINGS NEW JOBS TO MY TOWN EVEN IF IT MEANS A CHANGE IN THE CHARACTER AND TYPES OF BUSINESS IN MY COMMUNITY"?

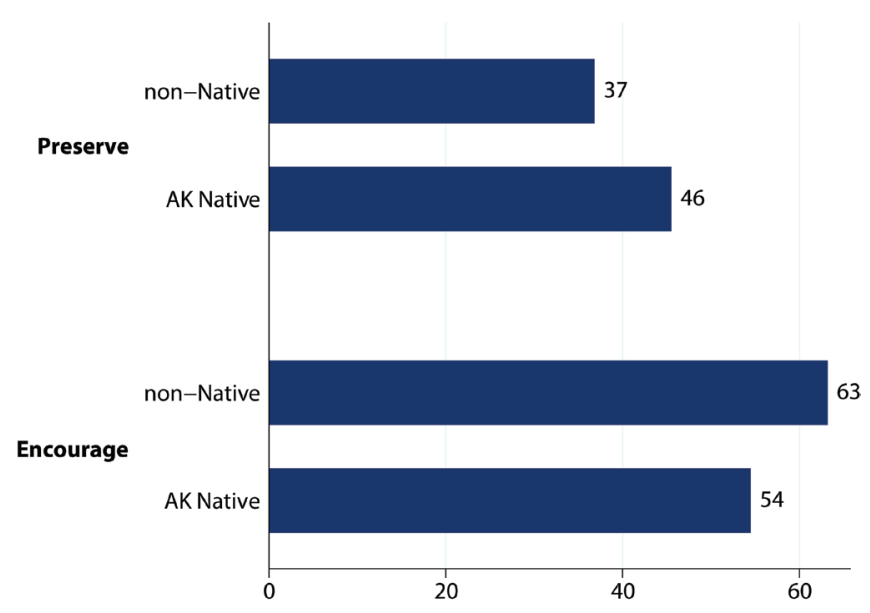

\section{Civic Culture and the Future of Rural Southeast Alaskan Communities}

Civic culture and local engagement are important dimensions of a community's social cohesion which can help increase resilience to social and economic disruptions. All segments of the population in KGB and PWH exhibited similar civic connections to their towns and villages as measured by perceptions of helpfulness of neighbors, community trust and cohesion, community working together, and effectiveness of local government (see Figure 7). Community engagement levels which were also similar were measured by respondents' participation in local organizations, and volunteer work.

Unlike other parts of rural America with high proportions of minority populations, there appears to be little difference in perceptions of civic culture and community engagement across racial groups. ${ }^{15}$ Rather than perceiving lower levels of civic culture or participating less in community activities, Alaska Natives have higher levels of civic culture than nonNatives and only slightly lower levels of civic engagementbelonging to a local organization and doing volunteer work. That Natives say they volunteer or belong to fewer groups 
Figure 7. Perceived Civic Culture and Engagement

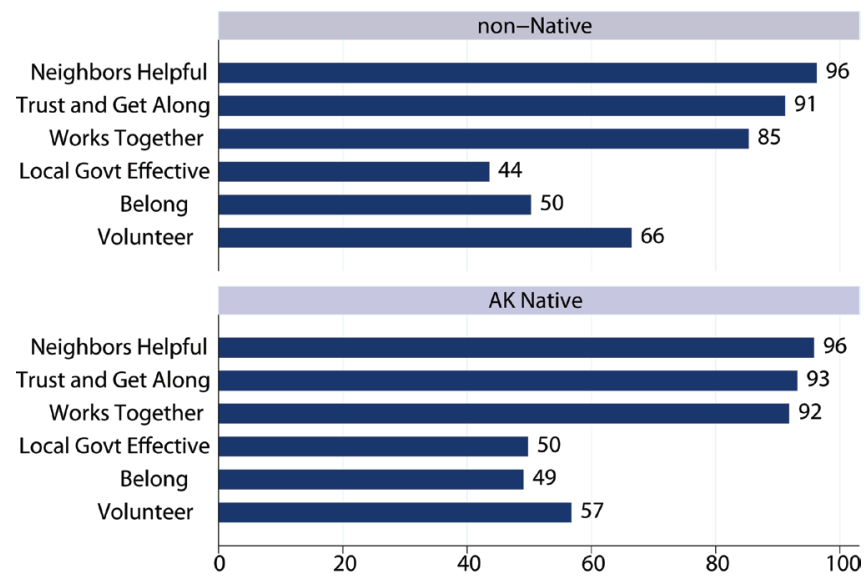

than non-Natives could reflect Alaska Natives' alternative ways of participating in their communities that are less formal than indicated in the survey questions.

Despite the strong civic culture in KGB and PWH, the sense that local government is ineffective in addressing social and environmental problems in their communities is striking. About half of all Southeast Alaskans do not think their local government has the ability to deal effectively with pressing issues in the region. When these data are combined, the results suggest that Southeast Alaskans may see community organizations founded upon bonds of trust, rather than government agencies, as the appropriate agents for addressing pressing social, economic, and environmental issues.

Finally, in the face of severe social and economic challenges, residents of KGB and PWH remain relatively optimistic about the future. When asked whether they thought their community would be a better place to live, a worse place, or about the same in ten years, most felt their community would remain the same, but 24 percent held a positive outlook, believing their town or village would be a better place (see Figure 8).

As in other CERA survey questions, Native and nonNative Alaskans have diverging opinions about the future of their communities. While 39 percent of Natives saw their community as being a better place in ten years, only about half of that amount (18 percent) of non-Natives thought their town or village would be a better place. On the opposite end of the spectrum, only 7 percent of Natives believe their communities will be worse places in the future in comparison to 17 percent of non-Natives. The relative differences among Native and non-Native Alaskans may illustrate how connections to their tribe and the Alaskan land and seascapes influence Natives' increased optimism about the future. These positive outlooks about their communities may also be a reason why fewer Natives than non-Natives are planning to leave the area. The fact that many Southeast
Alaskans, and Natives in particular, are optimistic about the future even when facing severe economic difficulties is an asset that may help these communities collectively combat the region's social and environmental challenges and build a more prosperous future.

FIGURE 8. BASED ON WHAT YOU SEE OF THE SITUATION TODAY, DO YOU THINK THAT, TEN YEARS FROM NOW, YOUR COMMUNITY WILL BE A BETTER PLACE TO LIVE, A WORSE PLACE, OR ABOUT THE SAME?

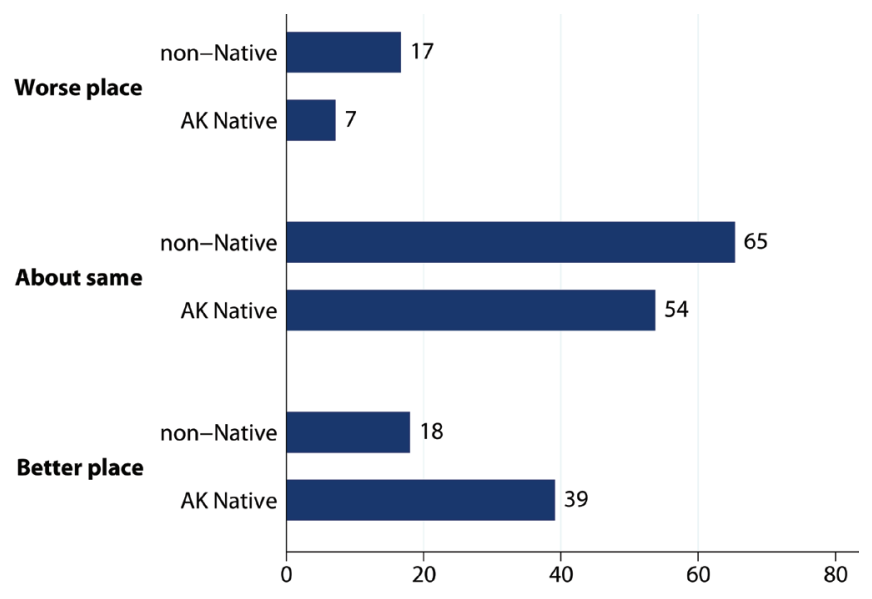

\section{Solutions Built on Understanding Social Ties to Community and the Environment}

Like much of rural America, Southeast Alaska is confronting the social implications of both population declines and the downturn in natural resource-based industries. Although many residents have chosen to leave Alaska in the last decade, the majority have stayed. Strong social cohesion and intimate ties to the natural amenities of the region are what sustain rural Alaskans. It is these connections to people and place that may ultimately enable residents to create renewed and more resilient Alaskan communities.

Southeast Alaskans see increasing opportunities within natural resource-related industries as well as promoting new forms of development as critical for job creation and economic improvement. However, residents understand that there are tradeoffs. Both conserving resources for future generations and maintaining the unique character of Alaskan towns and villages are important to a significant portion of the population. These connections to community and environment are especially strong among Alaskan Natives whose sense of commitment to their families, tribal culture, and natural environment is one of the region's strongest assets.

Although Southeast Alaskans are concerned about the local government's ability to address their communities' 
problems, the region's strong civic culture may be a resource that can be used to chart an alternative path forward. Policy makers and managers need to bolster residents' sense of civic engagement and understand the social as well as economic importance of natural resources and the Alaskan sea and landscapes. By doing so, they can overcome skepticism about governmental effectiveness and ensure that community groups as well as governmental agencies are working collaboratively to craft a robust economic future for the region.

Residents of KGB and PWH are actively thinking about these issues and should be directly involved in policy and management discussions. Fishery management programs that engage fishers and affected communities in decision making can draw upon the civic culture in the region as well as their commitment to the fishing industry to craft innovative solutions. Similarly forest managers need to consider the community impacts of reduced harvests, and local residents and civic organizations need to be engaged in discussing alternatives that produce economic benefits while also preserving the character of logging communities.

Tourism and other non-extractive activities are likely critical to the region's future. However, while they do not have the same level of degradation associated with them, transforming working waterfronts and mills into retail and service activities linked to tourism could have implications for the identity of rural Alaskan communities. Thus, these changes must be balanced against the benefits and impacts associated with traditional extractive endeavors. Promoting collaborative approaches that enable local residents to participate in these deliberations will likely help identify socially and environmentally sustainable alternatives.

Findings from the CERA survey in Southeast Alaska as well as other regions of rural America illustrate the interrelationships between social and environmental concerns. While regions like Southeast Alaska have unique social and natural characteristics, they share common challenges relating to the use of natural resources, changing demographics, and a civic culture that may be an asset to bolster residents' efforts to collectively chart an alternative future for their towns and villages. Through the CERA project, the Carsey Institute will continue to support these efforts by generating policy-relevant social and environmental data that captures both key local issues as well as national trends affecting all rural Americans.

\section{E N D N O T ES}

1. All percentages using CERA data throughout this brief are calculated using census-based age, race, and sex weights.

2. The term "Native" refers to self-identified indigenous people of Alaska such as Aleut, Inuit, Tsimshian, Haida, and Tlingit. Thus this may include people who are only part Native but who identify Native as their dominant race. "Non-Native" simply refers to anyone who did not identify "Native" as their primary race.

3. Of those interviewed, 392 (77 percent) were from KGB and 117 (23 percent) were from PWH. Of the 392 respondents from KGB, 380 were residents of Ketchikan city, while the remaining 12 respondents were from Ward Cove and Saxman. This means that three out of every four (75 percent) of all respondents were from Ketchikan city. Seventy-eight percent of non-Natives and 66 percent of Natives were from Ketchikan city. The U.S. Census Bureau reports that Ketchikan city is by far the largest community in the region with a population of 7,515 (out of a total of 18,565 for the entire region), thus it is not surprising that a large percentage of both Native and non-Native respondents were from the city. U.S. Census Bureau, "Population Estimates-Incorporated Places and Minor City Divisions" (Washington, DC: U.S. Census Bureau, 2010).

4. Rather than being divided into counties (or parishes in Louisiana) as all other U.S. states, the state of Alaska is divided into boroughs and census areas (sometimes referred to as unorganized boroughs).

5. United States Department of Agriculture, "Tourism and its Effects on Southeast Alaska Communities and Resources: Case Studies from Haines, Craig, and Hoonah Alaska" (Portland, OR: United States Department of Agriculture, Forest Service, Pacific Northwest Research Station, 2005), 17.

6. U.S. Census Bureau, "State and County Quick Facts" (Washington, DC: U.S. Census Bureau, 2010).

7. It should be noted that this is the weighted percent. If Census-based weights on sex, race, and age are not applied, only 17 percent of the respondents identified as being Native.

8. Southeast Conference and Central Council Tlingit and Haida Indian Tribes of Alaska, Southeast Alaska Comprehensive Economic Development Strategy, June 2006, 13.

9. Alaska was purchased in 1867 by the United States from Russia but did not become a state until 1959, meaning there was no U.S. Census recorded on a borough/Census area level in Alaska until 1960. Although past population data exists, this brief demographic description focuses on population change during the past half century.

10. United States Department of Agriculture, "Social Conditions and Trends in Southeast Alaska" (Portland, OR: United States Department of Agriculture, Forest Service, Pacific Northwest Research Station, 2005). 


\section{CARSEY INSTITUTE}

11. U.S. Census Bureau, "State and County Quick Facts."

12. Ibid.

13. Approximately 19 percent of all CERA respondents plan to leave their communities within the next five years.

14. This may be related to the fact that more non-Natives than Natives are newcomers (moved to the region as an adult) to the community (62 percent in comparison to 30 percent, respectively). Natives also have more family ties to the region. While 81 percent of Natives had at least one parent grow up in the region, only 19 percent of non-Natives said the same.

15. See Chris Colocousis and Luke Rogers, "Race, Class, and Community in a Southern Forest-Dependent Region," Issue Brief No. 14 (Durham, NH: Carsey Institute, University of New Hampshire, 2010).

\section{ABOUT THE AUTHORS}

Jessica D. Ulrich is a doctoral student in the Department of Sociology at the University of New Hampshire and a research assistant at the Carsey Institute (jessicad.ulrich@ gmail.com).

Thomas G. Safford is a Carsey Institute faculty fellow and an assistant professor of sociology at the University of New Hampshire (tom.safford@unh.edu).

\section{A C K N OW LE D G E M EN T S}

The authors would like to thank Larry Hamilton and Justin Young for their assistance on this project as well as Cliff Brown for his helpful suggestions on content.

\section{A UNIVERSITY}

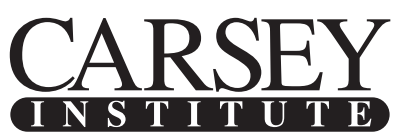

Building knowledge for families and communities

The Carsey Institute conducts policy research on vulnerable children, youth, and families and on sustainable community development. We give policy makers and practitioners timely, independent resources to effect change in their communities.

This work was supported by the Ford Foundation and W. K. Kellogg Foundation.

Huddleston Hall

73 Main Street

Durham, NH 03824

(603) $862-2821$

www.carseyinstitute.unh.edu 